Asian Pacific Journal of Reproduction

Journal homepage: www.apjr.net

\title{
Laser irradiation effects and its possible mechanisms of action on spermatozoa
} functions in domestic animals

\author{
Lone $\mathrm{SA}^{1 凶}$, Mohanty $\mathrm{TK}^{1}$, Kumaresan $\mathrm{A}^{2}$, Bhakat $\mathrm{M}^{1}$ \\ ${ }^{1}$ Artificial Breeding Research Centre, ICAR-National Dairy Research Institute, Karnal, 132001, Haryana, India \\ ${ }^{2}$ Livestock Research Centre, ICAR-National Dairy Research Institute, Karnal, 132001, Haryana, India
}

\section{ARTICLE INFO}

Article history:

Received 20 March 2017

Revision 6 April 2017

Accepted 20 April 2017

Available online 1 May 2017

\section{Keywords:}

Laser

Irradiation

Spermatozoa

Function

Mechanism

\section{ABSTRACT}

This article presents a review pertains the laser irradiation effects and its possible mechanisms of action on spermatozoa functions in domestic animals. To improve artificial insemination, laser is sensitive and cost effective technique, when compared to other conventional methods. Laser may have both positive and negative effects on spermatozoa functions. Since the effects of light are mediated by reactive oxygen species, and the levels of these reactive oxygen species following irradiating spermatozoa with laser may be responsible for determining the effects of laser on sperm. Dose of laser may be regarded as of great significance and this dosage of laser may be responsible for determining its effects on spermatozoa. Optimum dosage of laser for improving seminal attributes may vary among various species and this need to be standardized in each of them. The beneficial effects include improving sperm livability, acrosomal integrity, hypo-osmotic swelling response, mitochondrial function and computer-aided sperm analysis parameters. The increase in cytochrome c oxidase activity, ATP levels and mitochondrial membrane potential, in laser irradiated cells may be responsible for enhanced sperm quality parameters. Improving fertility with laser irradiated spermatozoa has been reported in few species like boar and need to be elaborated in other species. In conclusion laser may be regarded as an easy, cheap and time saving technology for improving artificial insemination; in addition, laser may have various potential applications in the field of reproductive biotechnology as well as in livestock farms and veterinary polyclinics.

\section{Introduction}

Cryopreservation of spermatozoa has led to wider application of artificial insemination. But following cryopreservation, sperm quality reduces which in turn decreases its fertility[1]. Exposure to various stresses during cryopreservation alters sperm physically and also leads to changes in chemical components which are needed for energy metabolism of sperm to support motility[2]. Sperm mitochondrial damage occurs due to destabilization of sperm membranes during freezing-thawing procedures, leading to impaired sperm motility and their capability to survive in the female genital tract[3]. To date, most of the researches have been focused to find

\footnotetext{
Corresponding author: Dr Shabir Ahmad Lone, Ph. D Scholar Animal Reproduction Gynaecology and Obstetrics, ICAR-National Dairy Research Institute, Karnal, 132001, Haryana, India.

Tel: 9138105720

Fax: +91-184-2250042

E-mail: drloneshabir@gmail.com
}

out suitable extenders to improve procedures for freezing[4] and/ or to protect spermatozoa by use of various additives[5,6], during freezing-thawing process[7]. Sperm mitochondrial function could negatively be affected by use of certain cryoprotectants namely soy lecithin, as revealed by previous findings[8]. So various other strategies aimed to improve sperm mitochondrial function need to be evaluated. Regarding this photobiostimulation of spermatozoa with a low-intensity helium-neon (He-Ne) laser has been shown to improve its motility[9]. Photobiostimulation of sperm was first reported in 1969[10], which has been proven in various species such

This is an open access article distributed under the terms of the Creative Commons Attribution-Non Commercial-Share Alike 3.0 License, which allows others to remix, tweak and buid upon the work non-commercially, as long as the author is credited and the new creations are licensed under the identical terms.

For reprints contact: reprints@medknow.com

C2017 Asian Pacific Journal of Reproduction Produced by Wolters Kluwer- Medknow

How to cite this article: Lone SA, Mohanty TK, Kumaresan A, Bhakat M. Laser irradiation effects and its possible mechanisms of action on spermatozoa functions in domestic animals. Asian Pac J Reprod 2017; 6(3): 97-103. 
as human[11], mouse[12], sheep[13], dog[14,15], avian[16], and rabbit[17] sperm.

\section{Effects of laser irradiation on spermatozoa functions in domestic animals}

The effects of laser irradiation on spermatozoa functions in various domestic animals are presented as follows.

\subsection{Cattle}

Livestock production depends highly on milk-producing animals particularly on cattle and buffalo and contributes to agricultural income-generation, food security, agro-industries and animal products' and animal production trade. As reported by Austin[18] and Chang[19], spermatozoa must reside inside the genital tract of female in order to become capable of fertilizing an oocyte, however many efforts have been made to eliminate the need of female reproductive tract in capacitation process. A variety of in vitro capacitating methods for mammalian spermatozoa including exposure to bovine serum albumin, serum, follicular fluid, cumulus cells, adrenal extracts and Sendai virus[20,21]. Ocafia-Quero et al.[22] studied effects of He-Ne laser irradiation with fluences from 2 to $16 \mathrm{~J} / \mathrm{cm}^{2}$ at $632 \mathrm{~nm}$ on acrosome reaction in bull spermatozoa. They revealed that laser irradiation significantly increases percentage of acrosome reacted spermatozoa and decreases percentage of in vitro dead spermatozoa at $90 \mathrm{~min}$ of incubation in comparison to other capacitation agents and the control group. The number of acrosome reacted spermatozoa increased and percentage of dead spermatozoa was proportional to intensity of fluencies. In another study, Fernandes et al.[23] used aluminum gallium indium phosphide laser with a wavelength of $660 \mathrm{~nm}$ and power of $30 \mathrm{~mW}$, to study the effect of low-level laser irradiation on sperm motility, plasma membrane integrity and acrosomal integrity in cryopreserved bull semen (Bos taurus indicus). Bull semen was divided into three groups viz., control group without lased irradiation, a $4 \mathrm{~J}$ group exposed to a laser irradiation dose of 4 joules (133 s of irradiation), and a $6 \mathrm{~J}$ group exposed to irradiation dose of 6 joules (200 s of irradiation), prior to freezing. The results revealed that there was an increase in percentage of membrane intact (live) and acrosome intact spermatozoa in $4 \mathrm{~J}$ and $6 \mathrm{~J}$ group. However, in preserving sperm motility, the dose of 4 joules was more effective than 6 joules.

\subsection{Buffalo}

Buffalo is one of the favorite animals in many countries, contributing around $52 \%$ of total milk products. It is presumed that enhancing its spermatozoa motility will have a promising effect on artificial insemination both qualitatively and quantitatively. Since motility of spermatozoa depends on amount of energy consumption, a higher energy supply to sperms will have a significant effect on their motility. Abdel-Salam et al.[24] studied the effect of laser irradiation (fluences ranging from 0.076 to $0.380 \mathrm{~J} / \mathrm{cm}^{2}$ ) at $532 \mathrm{~nm}$ on buffalo semen. They found that low laser irradiation doses $(0.31$ and 0.38$) \mathrm{J} / \mathrm{cm}^{2}$ for 4-5 min improved progressive motility, sperm velocity (VAP, VCL, VSL), distance (DAP, DCL, DVL), and ALH.

\subsection{Ram}

Cryopreservation modifies sperm functional and behavioral capacity, reduces sperm motility, their capacities to pass through the cervix and decreases the number of viable spermatozoa in female reproductive tract[25]. This is one of the leading reasons for lower pregnancy rates in ewes inseminated with frozen-thawed semen[26]. It becomes necessary to find out some new alternative techniques to cryopreservation for improving quality of frozen-thawed semen. On exposing tilapia and ram spermatozoa with red light 630-670 $\mathrm{nm}$ and white light 400-800 $\mathrm{nm}$, revealed an increase in motility and viability of tilapia sperm with both wavelengths while as only red light was effective in increasing sperm motility and viability in case of ram[13]. Irradiating cryopreserved ram semen after thawing to He-Ne laser with two different energy doses $\left(3.96\right.$ and $6.12 \mathrm{~J} / \mathrm{cm}^{2}$ ) reported that lower dose was ineffective in enhancing semen quality as compared to other irradiated samples and control. The comparison among various parameters viz., sperm viability, osmotic resistance, acrosomal integrity and DNA integrity between control and irradiated samples revealed no significant difference[27]. In another study, using similar laser and doses of energy (3.96 and $\left.6.12 \mathrm{~J} / \mathrm{cm}^{2}\right)$ revealed that $\mathrm{He}-\mathrm{Ne}$ laser irradiation leads to enhanced ram sperm motility, viability, mitochondrial function and hypo-osmotic swelling response at energy dose rate of $6.12 \mathrm{~J} / \mathrm{cm}^{2}$, in contrast to the dose of $3.96 \mathrm{~J} / \mathrm{cm}^{2}$ which reduces the quality of seminal attributes relative to the control sample[28]. Iaffaldano et al[7] conducted a research, in which frozen-thawed ram semen was irradiated with heliumneon laser irradiation with fluences ranging from 3.96-9 J/cm². Irradiation at $6.12 \mathrm{~J} / \mathrm{cm}^{2}$ significantly increased sperm motility and viability, however in other parameters such as osmotic resistance, DNA and acrosome integrity, no significant changes were reported. In sperms irradiated with laser, higher cytochrome c oxidase activity and ATP levels were reported than non-irradiated samples. Moreover, cytochrome c oxidase activity and ATP levels were positively correlated, and they also showed positive correlation with motility, suggesting that mitochondria-laser light interactions were responsible for enhanced semen quality in laser irradiated semen samples.

\subsection{Horse}

Brand`ao et al[29] subjected fresh and frozen equine spermatozoa with laser irradiation (650-nm) at energy dose of $6 \mathrm{~J} / \mathrm{cm}^{2}$ for 120 $\mathrm{s}$. The results revealed that in fresh semen samples, beat cross frequency was significantly higher for spermatozoa treated with 
laser than without laser treated. Immediately after thawing (0 min), mitochondrial membrane potential was significantly lower in spermatozoa treated with laser before freezing as compared to control. However, $2 \mathrm{~h}$ after thawing, plasma and acrosomal membrane integrity was significantly higher in spermatozoa treated with laser before freezing than control. In spermatozoa treated with laser after thawing, no significant difference in sperm parameters was observed $2 \mathrm{~h}$ after thawing, however, immediately after thawing, percentage of progressive motility was significantly lower than spermatozoa treated with laser before freezing and cryopreserved control samples.

\section{5. $\operatorname{Dog}$}

Subjecting fresh dog semen to irradiation doses of 4, 6 and $10 \mathrm{~J} /$ $\mathrm{cm}^{2}$ with a 655-nm continuous-wave diode laser and assessing it for various motility attributes with computer-aided sperm analysis (CASA) and sperm function tests, revealed that average path velocity (VAP), linear coefficient (Lin), beat cross frequency and functional tests were significantly different when compared to the control[14]. Corral-Baqués et al.[15] irradiated fresh dog semen with continuous wave diode laser $(655 \mathrm{~nm})$ with an average output power of $6.8 \mathrm{~mW}$, $15.4 \mathrm{~mW}, 33.1 \mathrm{~mW}$ and $49.7 \mathrm{~mW}$, respectively, and studied various motility parameters using CASA, at 0 and 45 min after irradiation. They reported that semen motility parameters were affected differently with various output powers, the most intense effects were observed with highest output power. Significant changes in motile sperm subpopulation were attributed to different output powers used.

\subsection{Boar}

Both intrinsic and extrinsic factors determine boar sperm quality, which in turn affects their reproductive performance. The intrinsic factors are breed[30], age[31] and size of testis[32] and extrinsic factors include semen handling[33], nutrition[34,35], environment[36], semen collection rhythm[37], temperature and photoperiod[38]. Daily variations in either natural or artificial light could only effect semen production in boar in extreme cases, particularly during dark hours[39]. Subjecting boar semen samples prior to AI to photostimulation could be a way to override reproductive performance variations in boars. Yeste et al.[40] observed the effect of different red light LED regimens on sperm quality and reproductive performance of boars. The best pattern was 10 min light, 10 min rest and 10 min of further light (10-10-10 pattern), which resulted in increase in majority of CASA based motility parameters with no change in sperm viability and acrosomal integrity in liquid stored boar semen. There was higher reduction in sperm quality parameters in nonexposed samples than laser irradiated samples following incubation for $90 \mathrm{~min}$ at $37^{\circ} \mathrm{C}$. Increase in percentage of sperm with high mitochondrial membrane potential due to laser exposure may be responsible for enhanced seminal attributes. Subjecting sperm to in vitro capacitation, percentage of spermatozoa with capacitation-like changes in membrane structure were higher in samples exposed to laser irradiation as compared to control ones. Laser treated (10-1010 pattern), semen samples prior to artificial insemination resulted in significantly higher farrowings rates and both total and live-born piglets.

\subsection{Rabbit}

Production of commercial rabbits for meat production depends exclusively on artificial insemination programs, but this technique is limited due to the fact that rabbit spermatozoa can be stored for a short length of time. Because of reduced survival of rabbit spermatozoa following long-term liquid storage and freezethawing procedures, all inseminations in rabbit are carried with fresh spermatozoa[41,42]. Thus development of novel procedures for enhancing quality of sperm is a goal to be pursued. Irradiating rabbit sperm cells with $\mathrm{He}-\mathrm{Ne}$ laser prevents in vitro storage damage. He-Ne laser irradiation improved rabbit sperm preservation during liquid storage modulating sperm qualitative functions. This effect may be related to the evidence of energetic biostimulation of rabbit spermatic cells and to an improved cytochrome c oxidase activity[17].

\subsection{Poultry}

Fertilizing capacity of cryopreserved poultry semen shows greater variation, which is responsible for its limited application for production or preservation of genetic stocks[43]. After cryopreservation, poultry spermatozoa are unable to maintain motility due to sensitivity to freeze-thaw procedures. One of the suitable goals to be achieved is developing new techniques for improving motility of avian spermatozoa after freezing thawing procedures. Differential action following $\mathrm{He}-\mathrm{Ne}$ laser irradiation of frozen-thawed turkey, chicken and pheasant spermatozoa has been reported. This work is first which elucidate the possibility for restoration of sperm motility in cryopreserved poultry spermatozoa following biostimulation with $\mathrm{He}-\mathrm{Ne}$ laser irradiation[44]. Previous works reported enhancement in quality of stored turkey semen following He-Ne laser irradiation with energy doses of $3.24 \mathrm{~J} / \mathrm{cm}^{2}$ to $5.40 \mathrm{~J} / \mathrm{cm}^{2}$ and particularly fluencies near to $4.00 \mathrm{~J} / \mathrm{cm}^{2}$ significantly reduced vitro liquid storage-dependent damage[16].

Microbial load is one of the essential quality attributes to be considered in semen used for artificial insemination or direct mating. Semen is an ideal medium for growth of microbes including bacteria and fungi and various other sources of its contamination are animals skin, mishandling of artificial vagina during semen collection, the processing equipment, animal handler, semen collector and laboratory personnel during manipulation. As reported by Bartlett[45], in frozen-thawed semen, a lower number of bacteria are accepted as normal due to high resistance of the endometrium of healthy animals to microbial infection. Normally antibiotics are added in 
the dilutor to check the growth of microorganisms[46,47], as these microbes impair semen quality due to production of reactive oxygen species. Due to application of a variety of antibiotics in extenders for reducing microbial growth, there is an emergence of antibiotic resistant strains and opportunistic and potential pathogens[48]. One of the novel methods for checking bacterial contamination in semen dilutors is use of laser irradiation. Hussein et al.[49] reported reduced microbial growth and enhanced semen quality in Friesian bulls following irradiating semen media with light emitting diode (680 $\mathrm{nm}, 10 \mathrm{~mW})$ and diode laser (660 nm, $100 \mathrm{~mW})$.

In bovine semen, random laser action by a Q-switched frequency doubled Nd: YAG laser was studied by Smuk et al.[50]. Laser induced breakdown spectroscopy (LIBS) and laser induced fluorescence (LIF) are some of the laser spectrochemical analytical techniques used for characterization of semen samples[51]. Using LIBS, AbdulSalam and Harith[51] used laser spectrochemical analytical techniques such as laser LIBS and laser induced LIF for characterization of semen samples. With the help of LIBS, it was possible to obtain information regarding the seasonal variations of elements in seminal plasma, and it was found that in buffalo bull seminal plasma, $\mathrm{Ca}$, $\mathrm{Mg}, \mathrm{Zn}$ and $\mathrm{Fe}$ were higher during winter season than summer season and the levels of these elements in seminal plasma were directly related to sperm parameters, suggesting that LIBS can be used as an indirect assay for semen parameters. LIF is generally used for identification of selective species and molecular structure studies, has been used for estimation of sperm concentration in semen samples. Sperm concentration could be correlated to the intensity of the emitted fluorescence and thus provided the basis for in situ rapid determination of sperm numbers, thus avoiding the use of microscopic or other time consuming imaging procedures in the laboratory[51].

\section{Possible mechanisms of laser action on spermatozoa}

Irradiation of sperm with laser leads to its increased respiration, fructose fermentation, ${ }^{32} \mathrm{P}$ uptake and the $\mathrm{Ca}^{2+}$ absorption, which increases motility and prolongs sperm survivability[52]. Photobiostimulation occurs when the light is absorbed by porphyrins, flavins or cytochromes and absorbed energy is transferred to oxygen molecules leading to generation of reactive oxygen species (ROS)[53]. ROS are responsible for mediating the effects of light[13]. ROS are known as double edged swords in animal reproduction as higher levels of ROS can lead to sperm death due to depletion of ATP and lipid peroxidation leading to oxidative stress[55] and moderate ROS levels regulate various physiological functions of sperm such as hyperactivation, capacitation, acrosomal reaction and zona binding[54,55]. Studies have shown elevated intracellular $\mathrm{Ca}^{2+}$ levels and its transport occurs in irradiated mouse[56] and bull spermatozoa[12,57]. This enhanced intracellular $\mathrm{Ca}^{2+}$ transport was responsible for regulating sperm motility, capacitation and the acrosome reaction[58] and in presence of calcium ions, fertilizing capacity of mouse sperm was improved by He-Ne laser irradiation[12]. Calcium mediates sperm activation through its action on axoneme and accessory cytoskeletal components[59,60]. In sperm mitochondria, oxidative phosphorylation leads to generation of ATP, which is primarily needed for sperm motility and it has been shown that energetic charge of cell was increased following laser irradiation[16].

As a result of prolonged storage, sperm mitochondrial ageing occurs, which leads to reduced sperm motility due to reduced capability to generate ATP through mitochondrial respiration[61,62]. In isolated mitochondria, He-Ne laser irradiation leads to an increase in ATP synthesis[63], RNA[64] and DNA synthesis[65], new mitochondria generation[66], activation of enzymes[67], modifications in substrate-enzyme interaction[68], and proton electrochemical potential[16] and it is evident that laser-induced protomotive force may be directly responsible for extra ATP synthesis. The sperm mitochondrial ATP is primarily needed for sperm motility[69], in addition, mitochondria also play a role in maintaining sperm tail contractability, eg. regulation of the membrane potential and flux of calcium[70,71]. Electron transfer chain is the common and final pathway in mitochondrial energy metabolism. Embedded in inner mitochondrial membranes is the electron transfer chain with two mobile carriers (Cytochrome $\mathrm{C}$ and Coenzyme $\mathrm{Q}$ ) and four multimeric enzymatic complexes (complexes I, II, III, and IV)[72]. A model proposed by Karu[73] revealed components of the respiratory chain (i.e. flavines, cytochromes) after absorbing light, cause the respiratory chain activation and the oxidation of the NAD pool, leading to changes in both mitochondrial and the cytoplasmic redox status. This alteration in redox status may impair transport of ions due to effect on permeability of membrane, which leads to changes in the ratio of $\mathrm{Na}^{+} / \mathrm{H}^{+}$, increase in $\mathrm{Na}^{+}, \mathrm{K}^{+}$, activity of ATPase, which in turn impairs $\mathrm{Ca}^{2+}$ flux. $\mathrm{Ca}^{2+}$ flux influences the levels of cyclic nucleotides, which in turn modulates synthesis of DNA and RNA, leading to cell proliferation. In particular, sperm motility is related with enzymatic activities of the sperm mitochondrial respiratory chain complexes, in which the apparent rate-limiting step is catalyzed by cyclo-oxygenase (COX) enzyme (or complex IV). A huge amount of oxygen in cells is consumed by COX, which is involved in reduction of dioxygen, acts as redoxlinked proton pump and is also responsible for generation of a transmembrane electrochemical gradient via coupling the free energy of water formation and eventually synthesis of ATP[74,75]. Sperm ATP contents showed positive correlation with progressive motility and COX activity was correlated with both mass and progressive motility[7].

Laser seems to alter somatic cell mitochondrial respiratory chain by changing the electric potential of cell membranes, their permeability to calcium, sodium and potassium ions or by elevating the activity of COX and ATP [9,63,76-78]. Positive correlations have been observed between COX activity with viability and acrosome intact 
spermatozoa. COX enzyme (or complex IV) appears to be involved in catalyzing rate-limiting step in sperm mitochondrial respiratory chain complexes, which are related to spermatozoa motility. Various attributes responsible for enhancing or reducing ATP availability or production particularly those that mediate mitochondrial function, could affect fertilizing capability of spermatozoa by changing motility[16]. COX activity is enhanced with He-Ne laser irradiation, which leads to proton pumping, needed for generation of the electrochemical proton gradient for driving ATP synthesis[7]. In avian semen, a high rate of species specific response to He-Ne laser biostimulation in terms of COX activity has been observed. Irradiation leads to enhanced COX activity in pheasant and turkey sperm, but not in chicken sperm. Variations originating from different energy metabolism of spermatozoa following photo-stimulation may be responsible for differential response of avian spermatozoa to irradiation[44]. It is reported that while turkey spermatozoa chiefly depend on mitochondrial oxidative metabolism for ATP and higher glycolysis activity has been observed in chicken spermatozoa for provision of ATP in anaerobic conditions[59]. Reduced Km values after He-Ne laser irradiation, indicates increased substrate enzyme affinity, and confirms the findings, where $\mathrm{Km}$ values for purified $\mathrm{COX}$ were declined in response to He-Ne laser subjection[67]. Timerelated reduction in sperm quality during refrigeration was declined by laser irradiation treatment and this may be due to elevated activity of COX and augmentation of EC in laser irradiated spermatozoa[17]. Thus by acting as a potent antioxidant, COX is involved in scavenging excess free radicals, generated in mitochondria.

\section{Conclusion}

In conclusion, laser is a cost effective and more sensitive technology which can be used for enhancing the artificial insemination system. The beneficial effects of laser on spermatozoa include increase sperm livability, acrosomal integrity, hypo-osmotic swelling response, mitochondrial function and CASA based sperm parameters (progressive motility, sperm velocity (VAP, VCL, VSL), distance (DAP, DCL, DVL), and ALH. The increase in these sperm attributes may be related to the fact that laser irradiation leads to higher cytochrome c oxidase activity, ATP levels and mitochondrial membrane potential, which in turn lead to enhanced sperm survival. Enhancing sperm survival using various doses of laser irradiation need to be standardized, in addition to this, fertility trials with laser irradiated spermatozoa and gene expression patterns in lased treated sperms in various species need to be conducted. Laser may be considered as double edged sword like ROS, as laser may have beneficial as well as harmful effects on spermatozoa of various species depending upon the dose of irradiation used. Dose of laser irradiation may be of paramount importance. Red light has been found to have more negative effects on sperm quality parameters[15]. Application of shorter laser wavelengths may be more reasonable for biostimulative purposes than longer laser wavelengths, because former are better absorbed by cellular chromophores than latter. To sum up, laser in the field of semen biology may be regarded as an easy, time saving, less costly and effective technique, in addition to other fields of reproduction like reproductive biotechnology and laser may have the possibility of its use in livestock farms and veterinary polyclinics.

\section{Conflict of interest statement}

We delcare that we have no conflict of interest.

\section{References}

[1] Watson PF. The causes of reduced fertility with cryopreserved semen. Anim Reprod Sci 2000; 60-61: 481-492.

[2] Long JA. Avian semen cryopreservation: What are the biological challenges? Poult Sci 2006; 85: 232-236.

[3] Gillan L, Maxwell WMC. The functional integrity and fate of cryopreserved ram spermatozoa in the female tract. J Reprod Fertil 1999; 54: 271-283.

[4] Emamverdi M, Zhandi M, Zare Shahneh A, Sharafi M, Akhlaghi A, Khodaei Motlagh M, et al. Flow cytometric and microscopic evaluation of post-thawed ram semen cryopreserved in chemically defined homemade or commercial extenders. Anim Prod Sci 2015; 55: 551-558.

[5] Succu S, Berlinguer S, Pasciu V, Satta V, Leoni GG, Naitana S. Melatonin protects ram spermatozoa from cryopreservation injuries in a dose-dependent manner. J Pineal Res 2011; 50: 310-318.

[6] Mata-Campuzano M, Álvarez-Rodríguez M, Álvarez M, TamayoCanul J, Anel L, de Paz P, et al. Post-thawing quality and incubation resilience of cryopreserved ram spermatozoa are affected by antioxidant supplementation and choice of extender. Theriogenology 2015; 83: 520528.

[7] Iaffaldano N, Paventi G, Pizzuto R, Dilorio M, Bailey JL, Manchisi A, et al. Helium-neon laser irradiation of cryopreserved ram sperm enhances cytochrome c oxidase activity and ATP levels improving semen quality. Theriogenology 2016; 86: 778-784.

[8] Del Valle I, Gómez-Durán A, Holt WV, Muiño-Blanco T, Cebrián-Pérez JA. Soy lecithin interferes with mitochondrial function in frozen-thawed ram spermatozoa. J Androl 2012; 33: 717-725.

[9] Karu TI. Lasers in infertility treatment: Irradiation of oocytes and spermatozoa. Photomed Laser Surg 2012; 30: 239-241.

[10]Goldstein SF. Irradiation of sperm tails by laser microbeam. J Exp Biol 1969; 51: 431-441.

[11]Lenzi A, Claroni F, Gandini L, Lombardo F, Barbieri C, Lino A, et al. Laser radiation and motility patterns of human sperm. Syst Biol Reprod Med 1989; 23: 229-234.

[12]Cohen N, Lubart R, Rubinstein S, Breitbart H. Light irradiation of mouse spermatozoa: Stimulation of in vitro fertilization and calcium signals. $J$ 
Photochem Photobiol B 1998; 68: 407-413.

[13]Zan-Bar T, Bartoov B, Segal R, Yehuda R, Lavi R, Lubart R, et al. Influence of visible light and ultraviolet irradiation on motility and fertility of mammalian and fish sperm. Photomed Laser Surg 2005; 23: 549-555.

[14]Corral-Baqués MI, Rigau T, Rivera M, Rodríguez JE, Rigau J. Effect of 655-nm diode laser on dog sperm motility. Lasers Med Sci 2005; 20(1): 28-34.

[15]Corral-Baqués MI, Rivera MM, Rigau T, Rodríguez-Gil JE, Rigau J. The effect of low-level laser irradiation on dog spermatozoa motility is dependent on laser output power. Lasers Med Sci 2009; 24(5): 703-713.

[16]Iaffaldano N, Meluzzi A, Manchisi A, Passarella S. Improvement of stored turkey semen quality as a result of He-Ne laser irradiation. Anim Reprod Sci 2005; 854: 317-325.

[17]Iaffaldano N, Rosato MP, Paventi G, Pizzuto R, Gambacorta M, Manchisi A, et al. The irradiation of rabbit sperm cells with He-Ne laser prevents their in vitro liquid storage dependent damage. Anim Reprod Sci 2010; 119: $123-129$.

[18]Austin CR. Observation of the penetration of sperm into the mammalian egg. Aust J Biol Res 1951; 4: 581.

[19]Chang MC. Fertilizing capacity of spermatozoa deposited in the fallopian tubes. Nature 1951; 168: 697.

[20]Rogers JBJ. Mammalian sperm capacitation and fertilization in vitro: A critique of methodology. Gamete Res 1978; 1: 165.

[21]Wright RW, Bondioli KR. Aspects of in vitro fertilization and embryo culture in domestic animals. J Animal Sci 1981; 53: 702.

[22]Ocaña-Quero JM, Gomez-Villamandos R, Moreno-Millan M, Santisteban-Valenzuela JM. Biological effects of helium-neon ( $\mathrm{He}-\mathrm{Ne})$ laser irradiation on acrosome reaction in bull sperm cells. J Photochem Photobiol B Biol 1997; 40: 294-298.

[23]Fernandes GHC, Carvalho PTC, Serra AJ, Crespilho AM, Peron JPS Rossato C, et al. The effect of low-level laser irradiation on sperm motility, and integrity of the plasma membrane and acrosome in cryopreserved bovine sperm. PLOS ONE 2015; 10(3): e0121487.

[24]Abdel-Salam Z, Dessouki SHM, Abdel-Salam SAM, Ibrahim MAM, Harith MA. Green laser irradiation effects on buffalo semen. Theriogenology 2011; 75: 988-994.

[25]Salamon S, Maxwell WMC. Frozen storage of ram semen I. Processing, freezing, thawing and fertility after cervical insemination. Anim Reprod Sci 1995; 37:185-249.

[26]Gillan L, Maxwell WMC. The functional integrity and fate of cryopreserved ram spermatozoa in the female tract. J Reprod Fertil 1999; 54: $271-83$.

[27]Ibrahim MAR, Zamfirescu S, Anghel A, Dobrin N, Ibrahim A, MeelSharawy, et al. The effects of helium-neon laser with different energy doses on cryopreserved ram semen quality in vitro examination. Sci Papers Series D: Anim Sci 2014; 57: 149-152.

[28]Nicolae D, Stela Z, Hortanse AA, Irina T, Iaffaldano N, Paventi G, Dragomir C. Study on the effects of exposure to different doses of energy generated by a He-Ne laser on the quality of frozen-thawed semen of ram. Rom Biotech Lett 2015; 20(3): 10381-10387.
[29]Brand^ao AC, Arruda RP, Andrade AFC, Zaffalon FG, Tarrag’o OFB, Visintin JA, et al. Effect of diode laser on motility, plasma and acrosomal membrane integrity, and mitochondrial membrane potential of cryopreserved stallion spermatozoa. Anim Reprod Sci 2008; 107(3-4): 309-310.

[30]Smital J, DeSousa LL, Mohsen A. Differences among breeds and manifestation of heterosis in AI boar sperm output. Anim Reprod Sci 2004; 80: 121-130.

[31]Huang YH, Lo LL, Liu SH, Yang TS. Age-related changes in semen quality characteristics and expectations of reproductive longevity in Duroc boars. Anim Sci J 2010; 81: 432-437.

[32]Clark SG, Schaeffer DJ, Althouse GC. B-mode ultrasonic evaluation of paired testicular diameter of mature boars in relation to average total sperm numbers. Theriogenology 2003; 60: 1011-1023.

[33]Leahy T, Gadella BM. Sperm surface changes and physiological consequences induced by sperm handling and storage. Reproduction 2011; 142: 759-778.

[34]Yeste M, Sancho S, Briz M, Pinart E, Bussalleu E, Bonet S. A diet supplemented with L-carnitine improves the sperm quality of Pietrain but not Duroc and Large White boars when photoperiod and temperature increase. Theriogenology 2010; 73: 577-586.

[35]Yeste M, Barrera X, Coll D, Bonet S. The effects on boar sperm quality of dietary supplementation with omega-3 polyunsaturated fatty acids differ among porcine breeds. Theriogenology 2011; 76: 184-196.

[36]Kunavongkrit A, Suriyasomboon A, Lundeheim N, Heard T, Einarsson S. Management and sperm production of boars under differing environmental conditions. Theriogenology 2005; 63: 657-667.

[37]Pruneda A, Pinart E, Briz MD, Sancho S, Garcia-Gil N, Badia E, et al. Effects of a high semen-collection frequency on the quality of sperm from ejaculates and from six epididymal regions in boars. Theriogenology 2005; 63: 2219-2232.

[38]Knecht D, Srodon S, Szulc K, Duzinski K. The effect of photoperiod on selected parameters of boar semen. Livest Sci 2013; 157: 364-371.

[39]Rivera MM, Quintero-Moreno A, Barrera X, Rigau T, Rodriguez-Gil JE. Effects of constant, 9-h and 16-h light cycles on sperm quality, semen storage ability and motile sperm subpopulations structure of boar semen. Reprod Domest Anim 2006; 41: 386-393.

[40]Yeste M, Codony F, Estrada E, Lleonart M, Balasch S, Peña A, et al. Specific LED-based red light photo-stimulation procedures improve overall sperm function and reproductive performance of boar ejaculates. Sci Rep 2016. doi: 10.1038/srep22569.

[41]Roca J, Martínez S, Vázquez JM, Lucas X, Parrilla I, Martínez EA Viability and fertility of rabbit spermatozoa diluted in Tris-buffer extenders and stored at $15{ }^{\circ} \mathrm{C}$. Anim Reprod Sci 2000; 64: 103-112.

[42]Mocé E, Vicente JS. Effect of cooling and freezing, the two first steps of a freezing protocol, on the fertilizing ability of the rabbit sperm. Reprod Nutr Dev 2002; 42: 189-196.

[43]Blesbois E, Brillard JP. Specific features of in vivo and in vitro sperm storage in birds. Animal 2007; 1: 1472-1481.

[44]Iaffaldano N, Paventi G, Pizzuto R, Passarella S, Cerolini S, Zaniboni L, et al. The post-thaw irradiation of avian spermatozoa with $\mathrm{He}-\mathrm{Ne}$ laser 
differently affects chicken, pheasant and turkey sperm quality. Anim Reprod Sci 2013; 142: 168-172.

[45]Bartlett DE. Bull semen: Specific microorganisms in disease control in semen and embryo. FAO Anim Health Prod 1981; 23: 29-48.

[46]Salamon S, Maxwell WMC. Storage of ram semen. Anim Reprod Sci 2000; 62: 77-111.

[47]Menchaca A, Pinczak A, Queirolo D. Storage of ram semen at $5{ }^{\circ} \mathrm{C}$ : effects of preservation period and timed artificial insemination on pregnancy rate in ewes. Anim Reprod 2005; 2: 195-198.

[48]Bielanski A. Disinfection procedures for controlling microorganism in the semen and embryos of humans and farm animals. Theriogenology 2007; 68: 1-22.

[49]Hussein ZM, El-Tayeb T, El-Keraby F, Harith MA. The effect of diode laser and light emitting diode on the bacterial contamination of semen medium for artificial insemination. Biologicals 2008; 36: 303-307.

[50]Smuk A, Lazaro E, Olson LP, Lawandy NM. Random laser action in bovine semen. Opt Commun 2011; 248: 1257-1258.

[51]Abdel-Salam Z, Harith MA. Laser spectrochemical characterization of semen. Talanta 2012; 99: 140-145.

[52]Wenbin Y, Wenzhong L, Mengzhao L, Baotian Z, Laizeng AI, Tongya

L. Effects of laser radiation on Saanen buck' s sperm energy metabolism. Beijing: Proceedings of the Sixth International Conference on Goats; 1996.

[53] Shahar S, Wiser A, Ickowicz D, Lubart R, Shulman A, Breitbart H. Lightmediated activation reveals a key role for protein kinase A and sarcoma protein kinase in the development of sperm hyper-activated motility. Hum Reprod 2011; 26(9): 2274-2282.

[54]Lone SA, Prasad JK, Ghosh SK, Das GK, Kumar N, Balamurugan B, et al. Effect of cholesterol loaded cyclodextrin (CLC) on lipid peroxidation and reactive oxygen species levels during cryopreservation of buffalo (Bubalus bubalis) spermatozoa. Asian PacJ Reprod 2016; 5(6): 476-480.

[55]Zhang W, Yi K, Chen C, Houa X, Zhou X. Application of antioxidants and centrifugation for cryopreservation of boar spermatozoa. Anim Reprod Sci 2012; 132: 123-128.

[56]Lubart R, Wollman Y, Friedmann H, Rochkind S, Laulicht I. Effects of visible and near infra-red lasers on cell cultures. J Photochem Photobiol B 1992; 12: 305-310.

[57]Breitbart H, Levinshal T, Cohen N, Friedmann H, Lubart R. Changes in calcium transport in mammalian sperm mitochondria and plasma membrane irradiated at $633 \mathrm{~nm}$ (He-Ne laser). J Photochem Photobiol B 1996; 34: 117-121.

[58]Darszon A, Treviño CL, Wood C, Galindo B, Rodríguez- Miranda E, Acevedo JJ, et al. Ion channels in sperm motility and capacitation. Soc Reprod Fertil Suppl 2007; 65: 229-244.

[59]Wishart GJ, Wilson YI. Temperature-dependent inhibition of motility in spermatozoa from different avian species. Anim Reprod Sci 1999; 57: 229-235.

[60]Ashizawa K, Wishart G, Tsuzuki Y. Avian sperm motility: Environmental and intracellular regulation. Avian Poult Biol Rev 2000; 11: 161-172.

[61]Cummins JM, Jequier AM, Kan R. Molecular biology of the human male infertility: Links with ageing, mitochondrial genetics and oxidative stress. Mol Reprod Dev 1994; 37: 345-367.
[62]Vishwanath R, Shannon P. Do sperm cell age? A review of the physiological changes in sperm during storage at ambient temperature. Reprod Fert Dev 1997; 9: 321-331.

[63]Passarella S, Casamassima E, Molinaro S, Pastore D, Quagliarello E, Catalano IM, et al A. Increase of proton electrochemical potential and ATP synthesis in rat liver mitochondria irradiated in vitro by heliumneon. FEBS Lett 1984; 175: 95-99.

[64]Greco M, Guida G, Perlino E, Marra E, Quagliariello E. Increase in RNA and protein synthesis by mitochondria irradiated with helium-neon laser. Biochem Biophys Res Commun 1989; 163: 1428-1434.

[65]Vacca RA, Marra E, Quagliariello E, Greco M. Activation of mitochondrial DNA replication by He-Ne laser irradiation. Biochem Biophys Res Commun 1993; 195: 704-709.

[66]Greco M, Perlino E, Pastore D, Guida G, Marra E, Quagliariello E. Helium-neon laser irradiation of rat liver mitochondria gives rise to a new subpopulation of mitochondria: isolation and first biochemical characterization. J Photochem Photobiol B 1991; 10: 71-78.

[67]Pastore D, Greco M, Passarella S. Specific helium-neon laser sensitivity of the purified cytochrome c oxidase. Int J Radiat Biol 2000; 76: 863870 .

[68]Gagliardi S, Atlante A, Passarella S. A novel property of adenine nucleotides: Sensitivity to helium-neon laser in mitochondrial reactions. Biochem Mol Biol Int 1997; 41: 449-460.

[69]Minelli A, Moroni M, Castellini C, Lattaioli P, Mezzasoma I, Ronquist G. Rabbit spermatozoa: a model system for studying ATP homeostasis and motility. J Androl 1999; 20: 259-266.

[70]Eddy EM, O’Brien DA. The spermatozoon. In: Knobil E, Neill JD, eidtors. The physiology of reproduction. New York: Raven Press; 1994, p. 29-77.

[71]Rossato M, Di Virgilio F, Rizzuto R, Galeazzi G, Foresta C. Intracellular calcium store depletion and acrosome reaction in human spermatozoa: Role of calcium and plasma membrane potential. Mol Hum Reprod 2001; 7: $119-128$

[72]Ruiz-Pesini E, Diez C, Lape^na AC, Pérez-Martos A, Montoya J, Alvarez E, et al. Correlation of sperm motility with mitochondrial enzymatic activities. Clin Chem 1998; 44: 1616-1620.

[73]Karu T. Molecular mechanism of the therapeutic effect of low intensity laser radiation. Lasers Life Sci 1988; 2: 53-74.

[74]Ruiz-Pesini E, Lape^na AC, Díez C, Alvarez E, Enríquez JA, LópezPérez MJ. Seminal quality correlates with mitochondrial functionality. Clin Chim Acta 2000; 300: 97-105.

[75]Richter OMH, Ludwig B. Cytochrome c oxidase- structure, function, and physiology of a redox-driven molecular machine. Rev Physiol Biochem Pharmacol 2003; 147: 47-74.

[76]Friedmann H, Lubart R, Laulicht I. A possible explanation of laser induced stimulation. J Photochem Photobiol B 1991; 11: 87-95.

[77] Tamura M. Non-invasive monitoring of the redox state of cytochrome oxidase in living tissue using near infra-red laser lights. Jpn Circ J 1993; 57: $817-824$.

[78]Koutná M, Janisch R, Veselská R. Effects of low-power laser irradiation on cell proliferation. Scr Med 2003; 76: 163-172. 